\title{
(2) OPEN ACCESS \\ Lumen-apposing metal stents for drainage of pancreatic fluid collections: does timing of removal matter?
}

\author{
Manu Nayar (D) ,' John S Leeds (D) ,' UK \& Ireland LAMS Colloborative, \\ Kofi Oppong
}

\begin{abstract}
${ }^{1}$ HPB Unit, Freeman Hospital, Newcastle upon Tyne, UK \& Population Health Sciences Institute, University of Newcastle upon Tyne, Newcastle upon Tyne, UK

${ }^{2}$ HPB Unit, Freeman Hospital Newcastle upon Tyne, UK \& Translational and Clinical Research Institute, University of Newcastle upon Tyne, Newcastle upon Tyne, UK
\end{abstract}

\section{Correspondence to}

Dr Manu Nayar, HPB Unit, Freeman Hospital, Newcastle upon Tyne, UK; manu.nayar@nhs.net

Received 5 August 2021 Accepted 25 January 2022
Check for updates

(c) Author(s) (or their employer(s)) 2022. Re-use permitted under CC BY-NC. No commercial re-use. See rights and permissions. Published by BMJ.

To cite: Nayar M, Leeds JS, UK \& Ireland LAMS

Colloborative, , et al. Gut Epub ahead of print: [please include Day Month Year]. doi:10.1136/

gutjnl-2021-325812

\section{MESSAGE}

Lumen-apposing metal stents (LAMS) are increasingly used for treatment of pancreatic fluid collections (PFC); some reports have recommended early removal due to an increased complication rate after 4-8 weeks. Analysing data from 18 UK and Ireland units retrospectively with a total of 1018 patients, initial bleeding was seen in only $1.1 \%$ of cases. During follow-up ( $\mathrm{n}=952)$, there were 63 significant delayed complications such as bleeding $(n=18)$ or buried stent $(n=45)$. None of the factors analysed such as type (walled off necrosis vs pseudocyst) size of collection or timing of removal (4-8 weeks vs. $>8$ weeks) showed a correlation with delayed advse events (AE). These results provide further indirect evidence for leaving LAMS in situ beyond 4 weeks if required clinically.

\section{IN MORE DETAIL}

LAMS have become the treatment of choice for treatment of PFCs primarily related to ease of use and perceived advantage of a large lumen to facilitate drainage and direct endoscopic necrosectomy. Reported AE include bleeding, sepsis, and perforation and buried stent syndrome. Predictors of immediate and late AE are controversial. Stent indwelling time beyond 4 weeks has been reported as a predictor of delayed bleeding and buried stent syndrome and a consensus has formed to remove LAMS by 4 weeks. However, this recommendation is based primarily on data from one cohort in one centre ${ }^{12}$ limiting the generalisability of the results.

A retrospective multicentre study involving 18 units from the UK \& Ireland was performed with the aim of investigating the technical and clinical success of LAMS (Hot AXIOS Stent) for PFC and the incidence of immediate and delayed $\mathrm{AE}$ and their associated risk factors. Data on LAMS placed for drainage of PFC in adults ( $>18$ years of age) between 2015 and 2019 were collected. As per UK and Irish republic guidance, ethical approval from an institutional review body was not required for this study. Institutional authorisation to hold a prospective patient database for use for quality improvement was obtained in each institution.

All procedures were performed by experienced endosonographers with a therapeutic echoendoscope. PFC were categorised in adherence to the revised Atlanta Criteria. ${ }^{3}$ Under EUS guidance, the PFC was assessed and punctured from the stomach or duodenum. The exact technique of puncture and
Key messages

What is already known on this topic

- With the increasing use of lumen-apposing metal stents (LAMS) for the treatment of pancreatic fluid collections (PFCs), there are reports of significant delayed events including buried stents and bleeding. The former could be related to the timing of removal of LAMS.

Why this study needed to be done

- The 4-week recommended interval for LAMS removal is based on data from a single centre thus limiting generalisability. Our study did not report increased rate of delayed events when the LAMS were removed beyond 4 weeks.

How this study might affect research, practice or policy

- Findings from the largest dataset in published literature adds to the existing knowledge on the use of LAMS for drainage of PFCs and its extended use in patients where clinically indicated. This will help promote further research in the treatment of PFCs.

use of ancillary imaging or techniques including fluoroscopy, balloon dilatation, nasocystic drain and/or placement of plastic pigtail stent within the LAMS was at the endoscopists' discretion. Stent removal was not to a set protocol but in the latter part of the study period, influenced by early data indicating increased $\mathrm{AE}$ with longer LAMS indwelling time, there was a consensus to aim to remove the LAMS within 4-6 weeks if possible. Patient related, procedural and post procedural data were recorded on a standard proforma in each unit. Follow-up data were collected in real time on the electronic patient record and when patients came back for stent removal.

Data were anonymised prior to transmission for compiling into a central dataset for analysis. A number of cases in the present study were included in previous publications. ${ }^{45}$

The outcomes of the study were technical success (index attempt), immediate $\mathrm{AE}$ and significant delayed AE. Technical success was defined as the ability to deploy LAMS in the correct position to enable drainage of the PFC. Clinical success was 
Table 1 Patient demographic details, pancreatic fluid collections (PFC) aetiology, PFC characteristics and procedure details

\begin{tabular}{llc}
\hline Age (years) & Median (IQR) & $54(43-64)$ \\
\hline Sex, $\mathrm{n}(\%)$ & Female & $420(41.3)$ \\
& Male & $598(58.7)$ \\
\hline Aetiology of pancreatitis, $\mathrm{n}(\%)$ & Gallstones & $488(47.9)$ \\
& Alcohol & $302(29.7)$ \\
& Idiopathic & $140(13.7)$ \\
& Other & $88(8.6)$ \\
\hline Type of collection, $\mathrm{n}(\%)$ & WON & $539(52.9)$ \\
& PC & $479(47.0)$ \\
\hline Size of collection (cm) & Median (IQR) & $11(9-14)$ \\
\hline Percentage necrosis & $<30 \%$ & $597(58.6)$ \\
& $>30 \%$ & $197(19.4)$ \\
\hline Procedure location, $\mathrm{n}(\%)$ & Endoscopy unit & $908(89.2)$ \\
& Operating theatre & $70(6.9)$ \\
Sedation & Intensive care unit & $40(3.9)$ \\
\hline X-ray screening used, $\mathrm{n}(\%)$ & Conscious sedation & $674(66.2)$ \\
& General anaesthesia/Propofol & $344(33.8)$ \\
\hline Stent size, $\mathrm{n}(\%)$ & No & $762(74.9)$ \\
& Yes & $256(25.1)$ \\
\hline Plastic stent, $\mathrm{n}(\%)$ & 10 mm & $128(12.6)$ \\
& 15 mm & $848(83.3)$ \\
& 20 mm & $42(4.1)$ \\
\hline & No & $861(84.6)$ \\
& Yes & $157(15.4)$ \\
\hline & No & $826(81.1)$ \\
& Yes & $192(18.9)$ \\
\hline & No & $976(95.9)$ \\
& Yes & $42(4.1)$ \\
\hline
\end{tabular}

defined as size of the PFC $<2 \mathrm{~cm}$ on cross-sectional imaging or at the time of stent removal whichever came first.

Immediate $\mathrm{AE}$ were defined as occurring within 24 hours of the procedure and included maldeployment, stent dislodgement, internal and external migration, and bleeding as defined by ASGE lexicon. ${ }^{6}$

Significant delayed AE were defined as clinically significant bleeding occurring beyond 24 hours of LAMS placement and buried stent. A buried stent was defined as the finding of internal migration of LAMS or tissue overgrowth and failure to remove at the time of initial removal attempt.

Analyses were performed to examine factors associated with significant delayed $\mathrm{AE}$. As data were compiled from a large number of centres, analyses were performed using multilevel statistical methods. Two-level models were used with patients nested within centres. Due to the binary nature of the outcome, the analyses were performed using multilevel logistic regression (Stata V.14). First, the separate association between each factor and $\mathrm{AE}$ was assessed in a series of univariable analyses. Subsequently, the joint association between variables was examined in a multivariable analysis. A backwards selection procedure was used to retain only the statistically significant variables. All clinically relevant variables were included as predictor variables.

A total of 1018 patients underwent EUS-guided drainage of PFC (WON 52.9\%, PC 47.1\%) with LAMS between October 2015 and January 2020. Table 1 details patient demographic details, PFC aetiology, PFC characteristics and procedure details.

Technical success was achieved in $97.1 \%$ (988/1018) patients. Immediate $\mathrm{AE}$ occurred in 3.8\% (39/1018) patients $(95 \% \mathrm{CI}$
$2.7 \%$ to $5.2 \%)$ that included bleeding in $1.1 \%(11 / 1018)$ patients (95\% CI $0.5 \%$ to $1.9 \%$ ) of which two patients who had bleeding had balloon dilatation performed. Three cases of bleeding were categorised as severe. Stent maldeployment occurred in 2.2\% (23/1018) patients (95\% CI $1.4 \%$ to 3.4\%) of which 13 were unspecified, 7 were within the cavity, 2 into colon and 1 within the stomach. In three patients, the reason for technical failure was not specified. One patient had a sedation-related adverse event.

Full follow-up information was available for 952 patients. Clinical success was recorded in $89.5 \%$ (852/952) (95\% CI 87.4\% to 91.4\%). Total delayed AEs occurred in $17.5 \%$ (167/952) patients (95\% CI $14.9 \%$ to $20.4 \%$ ). Significant delayed AE occurred in $6.6 \%$ (63/952) (95\% CI 5.1\% to 8.4\%) including buried stent in $4.7 \%(45 / 952)(95 \%$ CI $3.5 \%$ to $6.3 \%)$ and bleeding in $1.9 \%$ (18/952) (95\% CI $1.1 \%$ to $3.0 \%)$.

The other 104 delayed AE included external migration in 70, internal migration in 25, blocked stent in 8 and gastrocolonic fistula in 1.

Median time to attempted LAMS removal was 7 weeks (IQR $5-12), 80.2 \%(687 / 856)(95 \%$ CI $77.4 \%$ to $82.9 \%)$ had a removal of LAMS $>4$ weeks after insertion. The most common clinical reasons for the late removal of LAMS was a combination of patients with WONs still undergoing endoscopic necrosectomy and/or delayed ( $>4$ weeks) scheduled appointments for stent removal. The reason for late removal was not aetiology specific. Results of univariable analysis of factors associated with significant delayed AE are shown in table 2. On multilevel logistic regression, no variable was found to be associated with significant delayed AE.

\section{COMMENT}

LAMS with its unique single delivery design has the distinct advantage of ease of insertion in any facility (endoscopy unit, theatre or intensive care unit) without the use of ancillary equipment including guidewires and fluoroscopy for drainage of PFC. The present study represents the largest, multicentre cohort examining outcomes on the use of LAMS in patients with PFC. The study documented high technical (97.1\%) and clinical (89.5\%) success with immediate AE in 3.8\% and significant delayed $\mathrm{AE}$ in $6.6 \%$. The overall delayed AEs was $17.5 \%$.

The technical success rate is in keeping with that previously reported ${ }^{47}$ finding of a delayed bleeding rate of $1.9 \%$ is in keeping with previous studies. ${ }^{8-12}$ In the present study, significant delayed $\mathrm{AE}$ were not associated with the interval between LAMS insertion and removal a number of previous studies have suggested a significant increase in bleeding risk when LAMS are left in situ for more than 4 weeks. ${ }^{12}$ However, a recent literature review of bleeding events post LAMS placement identified 21 studies involving 1378 patients with a bleeding rate of $3.8 \%$ of which $46.2 \%$ occurred in the first week post LAMS placement. ${ }^{12}$

In contrast to our findings of no difference in $\mathrm{AE}$ between WOPN and PC and possible association of balloon dilatation with immediate AEs, a recent international multicentre study among 328 patients reported overall $\mathrm{AE}$ to be more likely in WOPN versus PC and cases with AEs were less likely to have undergone balloon dilatation of the tract. ${ }^{5}$ The reasons underlying the differences in these studies are not easily identifiable; however, the present study was conducted in a much larger cohort across multiple centres. Whether there are differences in patient assessment or selection criteria for which patients undergo LAMS insertion cannot be assessed. 
Table 2 Univariable analyses of factors associated with delayed bleeding and buried stent syndrome

\begin{tabular}{|c|c|c|c|c|}
\hline Variable & Category & Adverse event $\mathrm{n} / \mathrm{N}(\%)$ & ORs $(95 \% \mathrm{Cl})$ & $P$ value \\
\hline Case per unit $†$ & - & - & 1.04 (0.98 to 1.11$)$ & 0.16 \\
\hline Age $\dagger$ & - & - & 1.04 (0.88 to 1.24$)$ & 0.63 \\
\hline \multirow[t]{2}{*}{ Sex } & Female & $21 / 391(5.4 \%)$ & 1 & 0.20 \\
\hline & Male & $42 / 561(7.5 \%)$ & 1.43 (0.83 to 2.45 ) & \\
\hline \multirow[t]{4}{*}{ Aetiology } & Gallstones & $25 / 453(5.5 \%)$ & 1 & 0.56 \\
\hline & Alcohol & $23 / 285(8.1 \%)$ & 1.50 (0.84 to 2.70$)$ & \\
\hline & Idiopathic & $10 / 132(7.6 \%)$ & 1.40 (0.66 to 3.00$)$ & \\
\hline & Other & $5 / 82(6.1 \%)$ & 1.11 (0.41 to 2.99 ) & \\
\hline \multirow[t]{2}{*}{ Sedation } & Conscious & $38 / 637(6.0 \%)$ & 1 & 0.25 \\
\hline & GA / Propofol & $25 / 315(7.9 \%)$ & 1.36 (0.80 to 2.29$)$ & \\
\hline \multirow[t]{2}{*}{ Type collection } & WON & $27 / 505(5.4 \%)$ & 1 & 0.10 \\
\hline & Pseudocyst & $36 / 447(8.1 \%)$ & 1.55 (0.93 to 2.59$)$ & \\
\hline Cyst size * & - & - & 1.21 (0.91 to 1.61$)$ & 0.19 \\
\hline Cyst size & $\leq 10 \mathrm{~cm}$ & $30 / 448(6.7 \%)$ & 1 & 0.93 \\
\hline (categorical) & $>10 \mathrm{~cm}$ & $33 / 504(6.6 \%)$ & 0.98 (0.58 to 1.63$)$ & \\
\hline \multirow[t]{2}{*}{ Necrosis } & $<30 \%$ & 40/564 (7.1\%) & 1 & 0.16 \\
\hline & $>30 \%$ & $8 / 190(4.2 \%)$ & $0.58(0.26$ to 1.25$)$ & \\
\hline Time to stent & $\leq 4$ weeks & $11 / 169(6.5 \%)$ & 1 & 0.58 \\
\hline removal & 4.1-8 weeks & $17 / 324(5.3 \%)$ & 0.80 (0.37 to 1.75$)$ & \\
\hline attempt $\ddagger$ & $>8$ weeks & $26 / 363(7.2 \%)$ & 1.12 (0.53 to 2.34$)$ & \\
\hline \multirow[t]{2}{*}{ Balloon dilation } & No & $57 / 807(7.1 \%)$ & 1 & 0.20 \\
\hline & Yes & $6 / 145(4.1 \%)$ & 0.57 (0.24 to 1.34$)$ & \\
\hline \multirow[t]{2}{*}{ Plastic stent } & No & $52 / 772(6.7 \%)$ & 1 & 0.76 \\
\hline & Yes & $11 / 180(6.1 \%)$ & 0.90 (0.46 to 1.76$)$ & \\
\hline \multirow[t]{2}{*}{ Nasocystic drain } & No & $60 / 912(6.6 \%)$ & 1 & 0.82 \\
\hline & Yes & $3 / 40(7.5 \%)$ & 1.15 (0.34 to 3.84 ) & \\
\hline \multirow[t]{3}{*}{ Stent size } & $8-10 \mathrm{~mm}$ & $8 / 122(6.6 \%)$ & 1 & 0.60 \\
\hline & $15 \mathrm{~mm}$ & $54 / 791(6.8 \%)$ & 1.04 (0.48 to 2.25 ) & \\
\hline & $20 \mathrm{~mm}$ & $1 / 39(2.6 \%)$ & 0.38 (0.05 to 3.10$)$ & \\
\hline Number of & 0 & $51 / 690(7.4 \%)$ & 1 & 0.13 \\
\hline \multirow[t]{2}{*}{ necrosectomies } & 1 & $8 / 113(7.1 \%)$ & 0.95 (0.44 to 2.07$)$ & \\
\hline & $2+$ & $4 / 149(2.7 \%)$ & 0.35 (0.12 to 0.97$)$ & \\
\hline
\end{tabular}

${ }^{*}$ OR given for a 5 -unit increase in variable.

tOR given for a 10-unit increase in variable

$\ddagger$ Analysis performed for patients who had a stent removed only.

The most common delayed AE was found to be buried stents with an overall rate of $4.7 \%$ and this appears to be a commonly reported issue with LAMS. Management of a LAMS that is not immediately removable endoscopically or has become embedded in the intestinal wall can be challenging and resource intensive. Patients often require additional imaging prior to reattempting removal, additional endoscopic measures such as the 'stentin-stent' technique or even surgery. Given the consequence of this AE, the ability to predict its occurrence would be valuable. However, no risk factors were identified in the present study and specifically, time from insertion to removal was not found to contribute to this AE. Delayed removal is sometimes necessary in patients with significant pancreatic necrosis with minimal clinical success at 4 weeks and these data support this approach. These findings from a real-life large dataset add to the existing literature on the use of LAMS for the drainage of PFCs and support the extended use LAMS in patients where clinically indicated.

Twitter Manu Nayar @drmanuknayar

Collaborators UK \& Ireland LAMS Colloborative: Aaron MCGowan (aaron. mcgowan@nhslothian.scot.nhs.uk, Centre for Liver and Digestive Disorders, Royal Infirmary of Edinburgh); Abdul Razack (abdul.razack@hey.nhs.uk, Hull University Teaching Hospitals); Alistair Makin (alistair.makin@mft.nhs.uk, Manchester Royal Infirmary); Andrew Hopper (andrew.hopper1@nhs.net, Department of infection, immunity and cardiovascular disease. Sheffield University, Sheffield Teaching Hospitals.); Barbara Ryan (BARYAN@tcd.ie, St, James's Hospital, Dublin); Bharat Paranandi (b.paranandi@nhs.net, Leeds Teaching Hospitals NHS Trust); Bong Sik Matthew Kim (mattbskim@gmail.com, Cambridge University Hospitals NHS Foundation Trust); Colin McKay (Colin.McKay@ggc.scot.nhs.uk, NHS Greater Glasgow and Clyde Health Board); Danny Cheriyan (dannycheriyan@beaumont. ie, Beaumont Hospital, Dublin); David Reffitt (david.reffitt@nhs.net, King's College Hospital, London); Douglas Thorburn (douglas.thorburn@nhs.net, Royal Free Hospital, London); Edmund Godfrey (edmund.godfrey@addenbrookes.nhs.uk, Cambridge University Hospitals NHS Foundation Trust); Gavin Johnson (gavin.johnson2@nhs. net, University College Hospital, London); Gerard McCabe (Gerard.mccabe6@nhs. Scot, NHS Greater Glasgow and Clyde Health Board); Geroge Gemenetzis (georgios. gemenetzis@glasgow.ac.uk, NHS Greater Glasgow and Clyde Health Board); Guru Aithal (guru.aithal@nottingham.ac.uk, NIHR Nottingham Biomedical Research Centre, Nottingham University Hospitals NHS Trust and the University of Nottingham, Nottingham, UK); Ian Penman (ian.penman@nhslothian.scot.nhs.uk, Centre for Liver and Digestive Disorders, Royal Infirmary of Edinburgh); Jayapal Ramesh (jayapal. ramesh@rlbuht.nhs.uk, Royal Liverpool and Broadgreen University Hospitals); Joe Geraghty (Joe.Geraghty@mft.nhs.uk, Manchester Royal Infirmary); John Devlin ( john.devlin@nhs.net, King's College Hospital, London); Jonathan Evans (jonathan. evans@liverpoolft.nhs.uk, Royal Liverpool and Broadgreen University Hospitals); Jonathan Potts (jonathan.potts@nhs.net, Royal Free Hospital, London); KhoonSheng Kok (Khoon-Sheng.Kok@liverpoolft.nhs.uk, Royal Liverpool and Broadgreen University Hospitals); Mark Love (Mark.Love@belfasttrust.hscni.net, Belfast Health and Social Care Trust); Martin James (martin.james@nuh.nhs.uk, NIHR Nottingham Biomedical Research Centre, Nottingham University Hospitals NHS Trust and the University of Nottingham, Nottingham, UK); Matthew Huggett (matthewhuggett@ 
nhs.net, Leeds Teaching Hospitals NHS Trust); Paul Bassett (paul@statsconsultancy. co.uk, Statsconsultancy Ltd); Ryan Scott (ryan.scott@belfasttrust.hscni.net, Belfast Health and Social Care Trust); Sathis Mogan (sathis.mogan@nnuh.nhs.uk, Norfolk and Norwich University Hospital); Simon Rushbrook (SIMON.RUSHBROOK@nnuh. nhs.uk, Norfolk and Norwich University Hospital); Steve Pereira (stephen.pereira@ ucl.ac.uk, University College Hospital, London); Suresh Venkatachalapathy (suresh. venkatachalapathy@nuh.nhs.uk, NIHR Nottingham Biomedical Research Centre, Nottingham University Hospitals NHS Trust and the University of Nottingham, Nottingham, UK); Tareq El Menabawey (telmenabawey@nhs.net, University College Hospital, London); Terry Wong (Terry.Wong@gstt.nhs.uk, Guys and St. Thomas' Hospital, London); Umesh Basavaraju (umesh.basavaraju@nhs.scot, Aberdeen Royal Infirmary); Vikrant Parihar (vikrant.parihar1@hse.ie, St, James's Hospital, Dublin); Wei On (aaron.on@nhs.net, Leeds Teaching Hospitals NHS Trust).

Contributors MN initiated the idea for the study, methodology, data collection and analysis and writing the manuscript and accepts full responsibility as guarantor. JSL and KO contributed to the methodology, analysis, data collection and writing of the manuscript. The UK \& Ireland LAMS collaborative actively contributed to the data for patients in this study.

Funding The authors have not declared a specific grant for this research from any funding agency in the public, commercial or not-for-profit sectors.

Competing interests None declared.

Patient and public involvement Patients and/or the public were not involved in the design, or conduct, or reporting, or dissemination plans of this research.

Patient consent for publication Not applicable.

Provenance and peer review Not commissioned; externally peer reviewed.

Open access This is an open access article distributed in accordance with the Creative Commons Attribution Non Commercial (CC BY-NC 4.0) license, which permits others to distribute, remix, adapt, build upon this work non-commercially, and license their derivative works on different terms, provided the original work is properly cited, appropriate credit is given, any changes made indicated, and the use is non-commercial. See: http://creativecommons.org/licenses/by-nc/4.0/.

\section{ORCID iDs}

Manu Nayar http://orcid.org/0000-0002-1196-3406

John S Leeds http://orcid.org/0000-0002-5140-6225

Kofi Oppong http://orcid.org/0000-0002-7381-7412

\section{REFERENCES}

1 Bang JY, Navaneethan U, Hasan MK, et al. Non-superiority of lumen-apposing metal stents over plastic stents for drainage of walled-off necrosis in a randomised trial. Gut 2019;68:1200-9.

2 Bang JY, Hawes RH, Varadarajulu S. Lumen-apposing metal stent placement for drainage of pancreatic fluid collections: predictors of adverse events. Gut 2020;69:1379-81.

3 Banks PA, Bollen TL, Dervenis C, et al. Classification of acute pancreatitis--2012: revision of the Atlanta classification and definitions by international consensus. Gut 2013;62:102-11

4 Venkatachalapathy SV, Bekkali N, Pereira S, et al. Multicenter experience from the UK and ireland of use of lumen-apposing metal stent for transluminal drainage of pancreatic fluid collections. Endosc Int Open 2018;6:E259-65.

5 Fugazza A, Sethi A, Trindade AJ, et al. International multicenter comprehensive analysis of adverse events associated with lumen-apposing metal stent placement for pancreatic fluid collection drainage. Gastrointest Endosc 2020;91:574-83.

6 Cotton PB, Eisen GM, Aabakken L, et al. A lexicon for endoscopic adverse events: report of an ASGE workshop. Gastrointest Endosc 2010;71:446-54.

7 Bekkali N, Nayar M, Leeds J. A comparison of outcomes between a lumen-apposing metal stent with electrocautery-enhanced delivery system and a bi-flanged metal stent for drainage of walled-off pancreatic necrosis. Endosc Int Open 201;05:E1189-96.

8 DeSimone ML, Asombang AW, Berzin TM. Lumen apposing metal stents for pancreatic fluid collections: recognition and management of complications. World J Gastrointest Endosc 2017;9:456-63.

9 Garcia-Alonso FJ, Sanchez-Ocana R, Peñas-Herrero I, et al. Cumulative risks of stent migration and gastrointestinal bleeding in patients with lumen-apposing metal stents. Endoscopy 2018;50:386-95.

10 Siddiqui AA, Kowalski TE, Loren DE, et al. Fully covered self-expanding metal stents versus lumen-apposing fully covered self-expanding metal stent versus plastic stents for endoscopic drainage of pancreatic walled-off necrosis: clinical outcomes and success. Gastrointest Endosc 2017;85:758-65.

11 Yang D, Perbtani YB, Mramba LK, et al. Safety and rate of delayed adverse events with lumen-apposing metal stents (LAMS) for pancreatic fluid collections: a multicenter study. Endosc Int Open 2018;6:E1267-75.

12 Ahmad W, Fehmi SA, Savides TJ, et al. Protocol of early lumen apposing metal stent removal for pseudocysts and walled off necrosis avoids bleeding complications. Scand J Gastroenterol 2020;55:242-7. 